\title{
Effect of Adjuvant Gemcitabine Combined with Low-dose 5-Fluorouracil and Cisplatin Chemotherapy for Advanced Biliary Carcinoma
}

\author{
YUJI MORINE, MITSUO SHIMADA, TETSUYA IKEMOTO, YUSUKE ARAKAWA, \\ SHUICHI IWAHASHI, YU SAITO, SHINICHIRO YAMADA and SATORU IMURA
}

Department of Surgery, Institute of Health Biosciences, Tokushima University Graduate School, Tokushima, Japan

\begin{abstract}
Background/Aim: The aim of this retrospective study was to clarify the effectiveness of chemotherapy with gemcitabine combined with low-dose 5-fluorouracil and cisplatin (GFP) for advanced biliary carcinoma after hepatectomy. Patients and Methods: Sixty-two patients had biliary carcinoma with lymph node metastasis, intrahepatic metastasis or positive surgical margins, including intrahepatic cholangiocarcinoma (IHC, $n=25)$, hilar cholangiocarcinoma (HC, $n=14)$, and gallbladder cancer $(G B C, n=23)$. Twentyeight patients (IHC; $n=9, H C ; n=8, G B C ; n=11)$ received adjuvant GFP chemotherapy. Results: We found no significant difference in clinicopathological factors in patients treated with or without adjuvant GFP chemotherapy. Overall, survival in the adjuvant GFP group was significantly better than that in the non-adjuvant GFP group (3-year survival: $61.9 \%$ vs. $8.8 \%, p<0.001)$, as was relapse-free survival. Conclusion: Adjuvant GFP chemotherapy after hepatectomy may be a promising option for improving surgical outcomes in patients with advanced biliary carcinoma.
\end{abstract}

Biliary carcinoma, which includes intrahepatic cholangiocarcinoma (IHCC), hilar cholangiocarcinoma (HC) and gallbladder carcinoma (GBC), may be a relatively uncommon malignancy in Western countries, but is one of the most lethal digestive tract tumours because of metastasis or invasion of the tumour directly into adjacent organs at diagnosis. In Japan, the

This article is freely accessible online.

Correspondence to: Yuji Morine, MD, Ph.D., FACS., Department of Surgery, Institute of Health Biosciences, University of Tokushima Graduate School, 3-18-15 Kuramoto-cho, Tokushima 770-8503, Japan. Tel: +81 886339276, Fax: +81 886319698, e-mail: ymorine@tokushima-u.ac.jp

Key Words: Adjuvant chemotherapy, biliary carcinoma, gemcitabine, GFP. incidence of biliary carcinoma has markedly increased over the past several decades. Vital statistics in 2013 in Japan showed that biliary carcinoma was the sixth leading cause of carcinoma deaths with an incidence of over 22 per 100,000 and a mortality rate of $\sim 15$ per 100,000 (1). Complete surgical resection provides the only chance of survival. Many surgeons have advocated aggressive surgery, including major hepatectomy, extended lymph node (LN) dissection and combined vascular resection for improving surgical outcomes (2-8). However, despite aggressive liver surgery, the prognosis after surgery remains unsatisfactory, with 5-year survival rates of $19-35 \%$ for HC (5-8), 32-53\% for GBC (9-11) and 23-29\% for IHCC (12-14). Moreover, several investigators have indicated that LN metastasis, intrahepatic metastasis and positive surgical margins in the bile duct are poor prognostic factors (12-15). Even with aggressive surgical resection, tumour relapse frequently occurs immediately after surgery, particularly in patients with poor prognostic factors. Nevertheless, no standard treatment before or after surgery has been established, even in patients with biliary carcinoma with high risk factors of recurrence. Therefore, a multidisciplinary strategy including adjuvant therapy is desirable before or after surgery, at least for those patients with poor prognostic factors.

For unresectable biliary carcinoma, gemcitabine alone has been regarded as the key antitumour agent (17); recently, gemcitabine combined with cisplatin became the new standard regimen based on the results of the ABC-02 trial (18). In Japan, several investigators have reported the efficacy of gemcitabine plus S-1, an oral anticancer drug consisting of tegafur as a prodrug of 5-fluorouracil (5-FU), 5-chloro-2,4-dihydroxypyridine and potassium oxonate, in advanced biliary carcinoma (18-21). However, adjuvant treatment after surgery has shown little impact on this malignancy, and combinations of effective chemotherapeutic agents and regimens have not been established. With the exception of periampullary carcinoma, only one randomized control trial has demonstrated the efficacy of the combination adjuvant therapy of mitomycin $\mathrm{C}$ and 5-FU for 
GBC (22). Most recently, a retrospective study on adjuvant therapy with gemcitabine plus S-1 chemotherapy after aggressive surgery significantly improved prognosis, with $57 \%$ survival at 5 years after surgery $(23,24)$.

In our institution, gemcitabine combined with low-dose 5FU and cisplatin chemotherapy (GFP) for unresectable biliary carcinoma was introduced in $2004(25,26)$. We further applied this regimen as adjuvant treatment after surgery for advanced biliary carcinoma, particularly in patients with $\mathrm{LN}$ metastasis, intrahepatic metastasis and a positive surgical margin. In this retrospective study, we investigated the clinical impact of adjuvant GFP chemotherapy after hepatectomy for advanced biliary carcinoma.

\section{Patients and Methods}

Study design and patient selection. Our sample included 62 patients with advanced biliary carcinoma, including patients with IHCC $(n=25), H C(n=14)$, and GBC $(n=23)$ admitted to our institution from 1995 to 2012, who had at least one or more of the following: LN metastasis, intrahepatic metastasis and microscopic positive surgical margins of the bile duct. All patients were pathologically diagnosed as having biliary carcinoma after hepatectomy, and final staging and curability were defined according to the seven edition of the tumour-node-metastasis classification system for malignant tumours published by the Union for International Cancer Control (UICC) (27). We introduced adjuvant GFP therapy for such patients in 2004. The eligibility criteria for adjuvant GFP chemotherapy were as follows: i) Eastern Cooperative Oncology Group performance status (ECOG PS) of 0-1; ii) adequate bone marrow function (white blood cell count of at least $3,000 / \mathrm{mm}^{3}$, platelet count of at least $100,000 / \mathrm{mm}^{3}$, haemoglobin level $>10.0 \mathrm{~g} / \mathrm{dl}$ ); iii) aspartate aminotransferase/alanine aminotransferase (AST/ALT) no more than 3.0 times the upper limit of normal, total bilirubin of $1.5 \mathrm{mg} / \mathrm{dl}$ or less; iv) serum creatinine of $1.5 \mathrm{mg} / \mathrm{dl}$ or less; and v) written informed consent. Consequently, 28 patients with advanced biliary carcinoma (IHCC; $n=9, \mathrm{HC} ; \mathrm{n}=8, \mathrm{GBC} ; \mathrm{n}=11$ ) received postoperative adjuvant chemotherapy with GFP, and were divided into two groups based on the administration or not of adjuvant GFP chemotherapy (adjuvant GFP group and non-adjuvant GFP group). The clinicopathological characteristics, including prognosis and tumour relapse, were compared with those not having postoperative adjuvant chemotherapy. None had received prior chemotherapy or irradiation before surgical resection. The toxicity of adjuvant GFP chemotherapy was also analysed. Adverse events were evaluated using the National Cancer Institute Common Terminology Criteria for Adverse Events (CTCAE) version 4.0 (CTCAE V4.0; available from URL: http://ctep.cancer.gov/reporting/ctc.html). Tumour markers and chest-abdominal computed tomographic (CT) scans were examined every 3 months during the first year after surgery. From the second year, tumour markers were examined every 3 months, and chestabdominal CT every 6 months. In principle, the duration of surveillance was 5 years after surgery. The mean follow-up period was 31.9 months (range=4.6-90.4 months) for the adjuvant GFP group and 23.1 months (range=5.5-143.6 months) for the non-adjuvant GFP group.

Adjuvant GFP therapy protocol. The GFP regimen was a single 4week course of treatment that included a triple combination of agents namely gemcitabine, 5 -FU, and cisplatin. Gemcitabine $\left(1,000 \mathrm{mg} / \mathrm{m}^{2}\right)$ was diluted with $100-\mathrm{ml}$ normal saline and administered intravenously over 30 minutes on days $1,8,15$ and 22 . Cisplatin at $3 \mathrm{mg} / \mathrm{m}^{2} /$ day and 5 -FU at $300 \mathrm{mg} / \mathrm{m}^{2} /$ day were given peripherally on days 1 to 5,8 to 12,15 to 19 and 22 to 26 , followed by a 2-week withdrawal from chemotherapy. Induction therapy with two cycles of GFP therapy started within at least 4 months of hepatectomy for patients meeting the eligibility criteria. In patients with positive surgical margins, outpatient therapy was continued with one dose every 2 weeks of gemcitabine and cisplatin intravenously, and one dose 5 days each week of oral tegafur/uracil $(300 \mathrm{mg})$. Chemotherapy was terminated for unacceptable toxicity, or by patient request. After tumour relapse, patients were able to receive second-line chemotherapy including radiotherapy at their physician's discretion.

Statistical analysis. All statistical analysis was performed using statistical software (JMP 8.0.1; SAS, Cary, NC, USA). Relationships for clinicopathological variables between the adjuvant GFP group and the non GFP group were analysed with the Chi-square and Mann-Whitney $U$-test. Survival curves were calculated using the Kaplan-Meier method and compared using the log-rank test. Statistical significance was defined as $p<0.05$.

\section{Results}

Clinical and tumour characteristics. Table I shows clinical and tumour characteristics of patients who received or did not receive adjuvant GFP chemotherapy. In the adjuvant GFP group, age tended to be higher and the proportion of males a little lower. Otherwise, there was no significant difference in tumour location between the two groups. LN metastasis occurred in $67.8 \%$ of the adjuvant GFP group and in $73.5 \%$ of the non-adjuvant group. Intrahepatic metastasis was observed in $28.6 \%$ of the adjuvant GFP group and $32.4 \%$ of the non-adjuvant group. Positive microscopically resected margins of the bile duct were present in $35.7 \%$ of the adjuvant GFP group and $20.6 \%$ of the non-adjuvant GFP group. The incidence of LN metastasis, intrahepatic metastasis and positive margins was not statistically different between the two groups. Union for International Cancer Control (UICC) primary tumour factor and UICC stage did not differ between the two groups. There was also no significant difference in serum CA19-9 levels between the two groups.

Operative procedures. The extent of hepatectomy did not significantly differ between the two groups. Overall, hepatic lobectomy was performed in $67.9 \%$ of the adjuvant GFP group and $58.8 \%$ of the non-adjuvant GFP group. An extrahepatic bile duct resection was performed in $57.1 \%$ of the adjuvant GFP group and $70.5 \%$ of the non-adjuvant GFP group. While the induction of systemic regional $\mathrm{LN}$ dissection was equivalent for the two groups, para-aortic LN dissection in the adjuvant GFP group was significantly infrequent compared with that in the non-adjuvant GFP group (17.9\% vs. 55.9\%, respectively, $p=0.002$ ) (Table I). 
Table I. Patient characteristics.

\begin{tabular}{|c|c|c|c|}
\hline Characteristic & $\begin{array}{c}\text { Adjuvant } \\
\text { GFP }(n=28)\end{array}$ & $\begin{array}{c}\text { No treatment } \\
(\mathrm{n}=34)\end{array}$ & $p$-Value \\
\hline Age, years: mean \pm SD & $70.9 \pm 6.8$ & $66.9 \pm 9.0$ & 0.092 \\
\hline \multicolumn{4}{|l|}{ Gender, $\mathrm{n}$} \\
\hline Male/female & $12 / 16$ & $23 / 11$ & 0.072 \\
\hline \multicolumn{4}{|l|}{ Tumor location, $\mathrm{n}$} \\
\hline $\mathrm{IHCC}$ & 9 & 16 & \multirow[t]{3}{*}{0.422} \\
\hline $\mathrm{HC}$ & 8 & 6 & \\
\hline GBC & 11 & 12 & \\
\hline \multicolumn{4}{|l|}{ Pathology, n } \\
\hline Papillary adenoca. & 0 & 1 & \multirow{7}{*}{0.603} \\
\hline Well diff. adenoca. & 14 & 11 & \\
\hline Moderately diff. adenoca. & 9 & 13 & \\
\hline Poorly diff. adenoca. & 4 & 5 & \\
\hline Adenosquamous ca. & 0 & 1 & \\
\hline Mucinous adenoca. & 0 & 1 & \\
\hline Other & 0 & 2 & \\
\hline \multicolumn{4}{|l|}{ Lymph node metastasis, $\mathrm{n}$} \\
\hline Positive/negative & $19 / 9$ & $25 / 9$ & 0.624 \\
\hline \multicolumn{4}{|l|}{ Intrahepatic metastasis, $\mathrm{n}$} \\
\hline Positive/negative & $8 / 20$ & $11 / 23$ & 0.748 \\
\hline \multicolumn{4}{|l|}{ Resected margin, $\mathrm{n}$ : } \\
\hline Positive/negative & $10 / 18$ & $7 / 27$ & 0.184 \\
\hline \multicolumn{4}{|l|}{ UICC $\mathrm{pT}$ factor, $\mathrm{n}$} \\
\hline $\mathrm{T} 1 / \mathrm{T} 2 / \mathrm{T} 2 \mathrm{a} / \mathrm{T} 2 \mathrm{~b} / \mathrm{T} 3 / \mathrm{T} 4$ & $1 / 8 / 3 / 4 / 5 / 7$ & $1 / 4 / 1 / 8 / 7 / 13$ & 0.384 \\
\hline \multicolumn{4}{|l|}{ UICC stage, $\mathrm{n}$} \\
\hline II/III, IIIA, IIIB/IVA, IVB & $1 / 9 / 18$ & $4 / 8 / 22$ & 0.326 \\
\hline \multicolumn{4}{|l|}{ CA19-9 level (U/L), n } \\
\hline Mean $(25-75 \% \mathrm{CI})$ & $\begin{array}{c}1757 \\
(739-2775)\end{array}$ & $\begin{array}{c}2923 \\
(781-5065)\end{array}$ & 0.470 \\
\hline \multicolumn{4}{|l|}{ Extent of hepatic resection } \\
\hline Right trisectionectomy & 0 & 2 & 0.178 \\
\hline Left trisectionectomy & 0 & 0 & \\
\hline Right hepatic lobectomy & 11 & 11 & \\
\hline Left hepatic lobectomy & 8 & 7 & \\
\hline Sectionectomy & 0 & 3 & \\
\hline S4a+5 hepatectomy & 8 & 4 & \\
\hline Gall bladder bed resection & 1 & 4 & \\
\hline Partial resection & 0 & 1 & \\
\hline \multicolumn{4}{|l|}{ Caudate lobectomy } \\
\hline Yes/no & $5 / 23$ & $11 / 23$ & 0.194 \\
\hline \multicolumn{4}{|c|}{ Extra-hepatic bile duct resection } \\
\hline Yes/no & $16 / 12$ & $24 / 10$ & 0.271 \\
\hline \multicolumn{4}{|c|}{ Regional lymph node dissection } \\
\hline Yes/no & $25 / 3$ & $28 / 6$ & 0.441 \\
\hline \multicolumn{4}{|c|}{ Para-aortic lymph node dissection } \\
\hline Yes/no & $5 / 24$ & $19 / 15$ & 0.002 \\
\hline
\end{tabular}

CA19-9: Carbohydrate antigen 19-9; GFP: gemcitabine combined with low-dose 5-fluorouracil and cisplatin chemotherapy; IHCC: intrahepatic cholangiocarcinoma; HC: hilar cholangiocarcinma; GBC: gallbladder carcinoma; SD: standard deviation; UICC: Union for International Cancer Control.

Survival outcomes. Overall survival curves for both groups are shown in Figure 1. The 3- and 5-year overall survival rates were $61.4 \%$ and $44.2 \%$ in the adjuvant GFP group, and $8.8 \%$ and $5.9 \%$ in the non-adjuvant GFP group, respectively.
Table II. Primary tumour relapse site with and without adjuvant gemcitabine combined with low-dose 5-fluorouracil and cisplatin (GFP) therapy after hepatectomy.

\begin{tabular}{lccc}
\hline & $\begin{array}{c}\text { Adjuvant } \\
\text { GFP group } \\
(\mathrm{n}=28)\end{array}$ & $\begin{array}{c}\text { Non-adjuvant } \\
\text { GFP group } \\
(\mathrm{n}=34)\end{array}$ & $p$-Value \\
\hline Mean time to relapse, years & 1.50 & 0.97 & 0.0345 \\
Relapse rate, n (\%) & $22(78.6 \%)$ & $31(91.1 \%)$ & 0.1609 \\
Site of tumour relapse, n (\%) & & & \\
$\quad$ Liver & $8(28.6 \%)$ & $20(58.8 \%)$ & 0.0172 \\
Lymph node & $8(28.6 \%)$ & $10(29.4 \%)$ & 0.9422 \\
Peritoneum & $4(14.3 \%)$ & $3(8.8 \%)$ & 0.4988 \\
Remote organ & $5(17.9 \%)$ & $3(8.8 \%)$ & 0.1914 \\
Local & $1(3.6 \%)$ & $3(8.8 \%)$ & 0.4906 \\
\hline
\end{tabular}

Sites of tumour relapse were multiple in some cases.

Adjuvant GFP chemotherapy significantly prolonged surgical outcomes in advanced biliary carcinoma after hepatectomy $(p<0.0001)$. Additionally, no significant prognostic factors were observed for these patients except for the administration of adjuvant GFP therapy.

In relapse-free survival, the adjuvant GFP group had a significantly better prognosis compared with the nonadjuvant GFP group ( $p=0.034$ ) (Figure 2). Twenty-two out of 28 patients $(78.6 \%)$ in the adjuvant GFP group and 31 out of 34 patients $(91.1 \%)$ in the non-adjuvant GFP group experienced relapse after hepatectomy (Table II). Adjuvant GFP chemotherapy tended to reduce the tumour relapse rate $(p=0.1609)$ and significantly inhibited hepatic recurrence after hepatectomy $(p=0.0172)$.

Toxicity. Adjuvant GFP chemotherapy was introduced at a mean of 58 days following hepatectomy (range $=25-117$ days). All patients were evaluated for toxicity, and toxicities were observed during treatment. Adjuvant GFP chemotherapy was generally well tolerated and there were no treatment-related deaths. CTCAE grade 3 or 4 hematological toxicities included leucopenia in 14 patients (50\%), thrombocytopenia in 13 patients (46.4\%) and anaemia in four patients (14.2\%). No patient with grade 3 or 4 neutropenia had febrile episodes. No CTCAE grade 3 or 4 non-hematological toxicities were observed.

\section{Discussion}

Biliary carcinoma has a poorer prognosis than other digestive malignancies because of metastasis or direct invasion into adjacent organs at diagnosis. Especially in patients with LN metastasis, intrahepatic metastasis and positive surgical margins of the bile duct, even aggressive surgical treatment might not Improve surgical outcomes (12-16). Our 


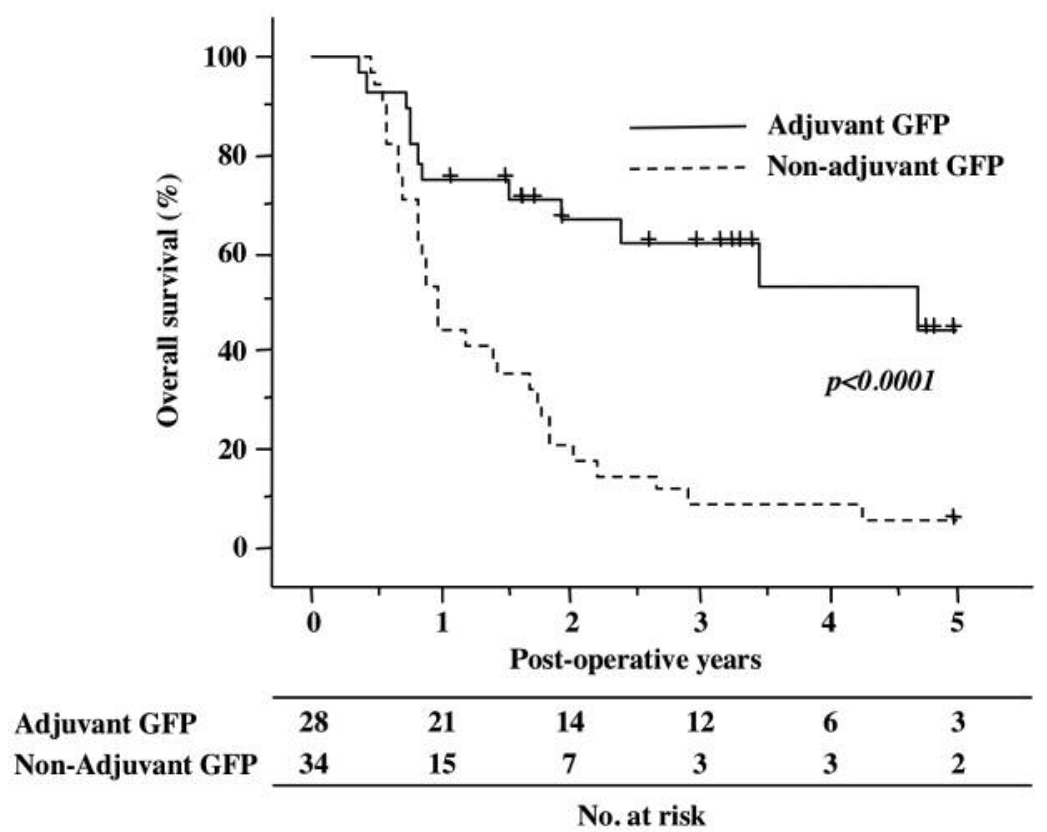

Figure 1. Overall survival curves of patients according to the administration or not of adjuvant low-dose 5-fluorouracil and cisplatin (GFP) chemotherapy after hepatectomy.

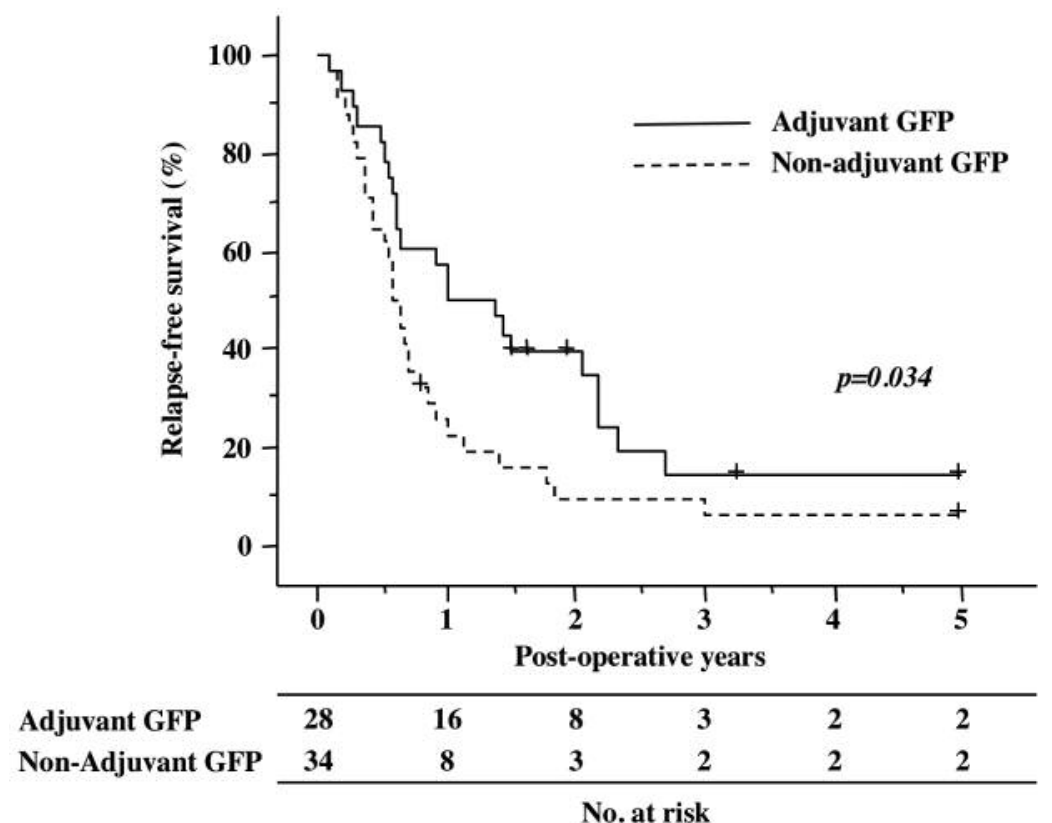

Figure 2. Relapse-free survival curves of patients according to the administration or not of adjuvant low-dose 5-fluorouracil and cisplatin (GFP) chemotherapy after hepatectomy.

retrospective study investigated the possibility of using adjuvant chemotherapy after hepatectomy for advanced biliary carcinomas. We found that adjuvant GFP chemotherapy for patients with LN metastasis, intrahepatic metastasis and positive surgical margins had improved surgical outcomes, with a 44.2\% 5-year survival rate after hepatectomy, and had acceptable toxicity. Although the tumour relapse rate remained high despite induction with 
Table III. Results of adjuvant chemotherapy after surgery for biliary carcinoma.

\begin{tabular}{|c|c|c|c|c|c|c|c|}
\hline \multirow[t]{2}{*}{ Author (Ref) } & \multirow[t]{2}{*}{ Study design } & \multirow[t]{2}{*}{ Regimen } & \multirow[t]{2}{*}{ Tumour } & \multicolumn{2}{|c|}{ Eligible criteria } & \multirow[t]{2}{*}{ Survival (\%) } & \multirow[t]{2}{*}{$p$-Value* } \\
\hline & & & & Curability & Tumor status & & \\
\hline \multirow[t]{2}{*}{ Takada et al. (22) } & \multirow[t]{2}{*}{ Phase III } & \multirow[t]{2}{*}{$\mathrm{MMC}+5-\mathrm{FU}$} & $\mathrm{HC}, \mathrm{DC}$ & $\mathrm{R} 0 / 1$ & Stage II-IV & $26.7 \% \mathrm{~V}$ & N.S. \\
\hline & & & GB & $\mathrm{R} 0 / 1$ & Stage II-IV & $26.0 \% \mathrm{~V}$ & 0.0367 \\
\hline Yamanaka et al. (33) & Historical cohort & GEM & $\begin{array}{l}\text { IHCC, HC, DC, } \\
\text { GBC, AC }\end{array}$ & R0 & None & $68.7 \%$ III & N.S. \\
\hline Nakamura et al. (34) & Case-control & GEM & GBC & $\mathrm{R} 1 / 2$ & None & $(66.4)^{\dagger}$ & 0.002 \\
\hline Murakami et al. (24) & Case-control & $\mathrm{GEM}+\mathrm{S} 1$ & $\mathrm{HC}, \mathrm{DC}, \mathrm{GBC}, \mathrm{AC}$ & $\mathrm{R} 0 / 1$ & UICC stage IIA/B & $57 \% \mathrm{~V}$ & $<0.001$ \\
\hline May et al. (35) & Phase II & $\begin{array}{c}\text { GEM+DOC } \\
\text { after } \mathrm{RT}+5-\mathrm{FU}\end{array}$ & $\mathrm{HC}, \mathrm{DC}, \mathrm{AC}$ & R0 & UICC stage I-III & $49.1 \% \mathrm{II}$ & --- \\
\hline Kainuma et al. (36) & Phase II & GEM+CDDP & $\begin{array}{l}\text { IHCC, HC, DC, } \\
\text { GBC, AC }\end{array}$ & $\mathrm{R} 0$ & None & $60 \% \mathrm{IV}$ & --- \\
\hline Park et al. (37) & Case-control & $\mathrm{RT}+\mathrm{GEM}$ or $5-\mathrm{FU}$ & $\mathrm{HC}, \mathrm{DC}$ & $\mathrm{R} 1 / 2$ & $\geq \mathrm{T} 2 / \mathrm{LN}$ met. & $11.5 \% \mathrm{~V}$ & --- \\
\hline Nelson et al. (38) & Case-control & $\mathrm{RT}+5-\mathrm{FU}$ & $\mathrm{HC}, \mathrm{DC}$ & NR & None & $33 \% \mathrm{~V}$ & --- \\
\hline Kim et al. (39) & Case-control & $\mathrm{RT}+5-\mathrm{FU}$ & $\mathrm{HC}, \mathrm{DC}$ & NR & No distant met. & $36.5 \% \mathrm{~V}$ & 0.049 \\
\hline Hughes et al. (40) & Case-control & $\mathrm{RT}+5-\mathrm{FU}$ & DC & NR & No distant met. & $35 \% \mathrm{~V}$ & --- \\
\hline Czito et al. (41) & Case-control & $\mathrm{RT}+5-\mathrm{FU}$ & GBC & NR & No distant met. & $37 \% \mathrm{~V}$ & --- \\
\hline Kresl et al. (42) & Case-control & $\mathrm{RT}+5 \mathrm{FU}$ & GBC & NR & None & $33 \% \mathrm{~V}$ & --- \\
\hline Our study & Case-control & GFP & $\begin{array}{l}\text { IHCC, } \mathrm{HC}, \\
\text { GBC }\end{array}$ & $\mathrm{R} 0 / 1$ & $\begin{array}{l}\mathrm{LN} \text { met./intrahepatic } \\
\text { met./positive margin }\end{array}$ & $44.2 \% \mathrm{~V}$ & $<0.001$ \\
\hline
\end{tabular}

MMC: Mitomycin C; GEM:gemcitabine; DOC:docetaxel; CDDP: cisplatin; IHCC:intrahepatic cholangiocarcinoma; HC:hilar cholangiocarcinoma; GBC: gallbladder carcinoma; DC: distal cholangiocarcinoma; AC: periampullary carcinoma; RT: radiotherapy; met: metastasis; UICC: Union for International Cancer Control. *vs. Surgery alone; ${ }^{\mathrm{II}_{2}-}$, III3-, IV 4 -year and $\mathrm{V}_{5}$-year; ${ }^{\dagger}$ mean survival (months), ${ }^{\ddagger}$ Japanese Society of Biliary Surgery (53).

adjuvant GFP chemotherapy, relapse-free survival also improved significantly with this strategy.

Gemcitabine-based chemotherapy is the standard anticancer agent for unresectable biliary carcinoma, and gemcitabine combined with cisplatin therapy has recently been used as firstline treatment in clinical settings because of the results of the ABC-02 trial (18). Likewise, several investigators have reported use of various adjuvant treatments after surgery, but the optimal multidisciplinary treatment has not yet been established. One meta-analysis revealed that chemotherapy or chemoradiotherapy had a statistically greater benefit than radiotherapy alone (32). It has also been reported that remote organ metastasis is more frequently observed than locoregional recurrence of biliary carcinoma after surgery (28-31). Therefore, adjuvant treatment with systemic chemotherapy might have some advantage in the regulation of recurrences after drastic local treatment such as surgery as compared with local radiotherapy. To our knowledge only one randomized control study has reported the efficacy of adjuvant therapy in biliary carcinoma, with the exception of adjuvant therapy for periampullary carcinoma. Takada et al. demonstrated that patients with GBC receiving adjuvant therapy consisting of mitomycin $\mathrm{C}$ and 5-FU after surgery had an improved overall survival (22). Some have recommended adjuvant chemotherapy and chemoradiotherapy after surgery for biliary carcinoma, as shown in Table III (21, 24, 33-42). However, the results of adjuvant external-beam radiation therapy with concurrent 5-FU treatment were unsatisfactory, with a 5-year survival rate of less than $40 \%(38-42)$. Therefore, it is still unclear whether adjuvant chemoradiotherapy based on 5-FU offers improved survival for patients with biliary carcinoma. Recently, gemcitabine-based adjuvant chemotherapy has been applied in this setting. Adjuvant gemcitabine alone was expected to improve the prognosis of patients with GBC after non-curative resections (34). Another study recommended that adjuvant gemcitabine alone might be effective in selected patients with either stage III biliary carcinoma or IHCC (33). Furthermore, adjuvant gemcitabine and S-1 combination chemotherapy has been introduced for its synergistic antitumour effect, and the regimen provided the best clinical impact for patients with UICC stage IIA/B biliary carcinoma, with a $57 \%$ survival rate at 5 years after aggressive surgery. More recently, Kainuma et al. investigated the feasibility and efficacy of gemcitabine combined with cisplatin for patients with biliary tract cancer after R0 resection of hepatectomy or pancreatodudenectomy in a single-arm phase II trial. In the near future, other gemcitabine-based combination chemotherapies such as gemcitabine combined with cisplatin, which was the first standard regimen for unresectable biliary carcinoma, might be tried as adjuvant treatment. 
Many investigators have not defined clear indicators for adjuvant treatment after surgery. In the one randomized trial mentioned above, the criteria for inclusion may have been too broad (R0/1 resection and stage II-IV) and thus the trial failed to show any clinical significance for adjuvant chemotherapy for extrahepatic biliary carcinoma. However, several investigators have noted that adjuvant therapy may be of value for particular indications. Glazer et al. indicated that neither neoadjuvant nor adjuvant chemotherapy for biliary carcinoma rescued patients with adequate negative margins $(>1 \mathrm{~cm})$ after surgery (43). Nakamura et al. also recommended adjuvant gemcitabine treatment for GBC only after non-curative resection (34). In a sub-group analysis, Yamanaka et al. suggested that the survival benefits were possibly modified by LN metastasis, stage III, IHCC, and poorly differentiated tumour, although survival probabilities with adjuvant chemotherapy in the analysis of all patients did not prove favourable (33). Other reports have indicated that the benefits of adjuvant chemotherapy were more likely to be found in patients who had high-risk features, including high level of lymphovascular invasion, LN metastasis, advanced stage, pT4 stage and R1 resection (44-46). Murakami et al. enrolled selected patients with UICC stage IIA/B biliary carcinoma as candidates for adjuvant gemcitabine plus S-1 chemotherapy after aggressive surgery (20). Two molecular biomarkers have been identified in clinical studies as being able to prove the efficacy of gemcitabine-based chemotherapy $(47,48)$. Murakami et al. suggested that combined analysis of intratumoural human equilibrative nucleoside transporter 1 (hENT1) and ribonucleotide reductase subunit 1 (RRM1) that are highly expressed was more useful for predicting the results of adjuvant gemcitabine-based chemotherapy after surgery in patients with biliary carcinoma. In the future, we might have to consider these predictive biomarkers for gemcitabinebased chemotherapy, as well as for indications for adjuvant chemotherapy after surgery.

In our trials, gemcitabine combined with low-dose 5-FU and cisplatin was introduced for biliary carcinoma. The combination of gemcitabine and cisplatin has been explored in several studies because the combination appears to be synergistic, based on laboratory data (49-52). Favourable results with GFP chemotherapy for unresectable biliary carcinoma have been reported in a pilot study $(25,26)$. Subsequently, this regimen was applied in adjuvant settings for hepatectomized patients with LN metastasis, intrahepatic metastasis and positive surgical margins of the bile duct, because even aggressive surgery has not improved surgical outcomes in patients with these prognostic factors. We showed favourable outcomes with acceptable toxicity. However, in our series, the 5-year survival rate was about $44 \%$, a little lower than that for adjuvant gemcitabine plus $\mathrm{S}-1$ chemotherapy. The difference in survival rate may be due to there being more advanced cases in our study (UICC stage III and IV). The limitations of our study are its retrospective design and small number of patients. The mean follow-up period was comparatively shorter in the adjuvant GFP group, therefore our results might be immature. Hence, the adjuvant GFP chemotherapy regimen warrants further detailed evaluation, using a well-designed randomized prospective investigation that includes biological activity as a stratification strategy.

In conclusion, our trial indicated that a regimen of gemcitabine combined with low-dose 5-FU and cisplatin is an active therapeutic option as adjuvant chemotherapy after hepatectomy for patients with LN metastasis, intrahepatic metastasis and positive surgical margins of bile duct in biliary tract carcinoma. While a randomized controlled trial with a larger number of patients is required to confirm the efficacy of adjuvant chemotherapy after surgery of biliary carcinoma, adjuvant GFP chemotherapy after surgery may be a promising option for improving surgical outcomes of patients with advanced biliary cancers.

\section{References}

1 Matsuda A, Matsuda T, Shibata A, Katanoda K, Sobue T and Nishimoto H; Japan Cancer Surveillance Research Group: Cancer incidence and incidence rates in Japan in 2008: a study of 25 population-based cancer registries for the monitoring of cancer incidence in Japan (MCIJ) Project. Jpn J Clin Oncol 44: 388-396, 2013.

2 Washburn WK, Lewis WD and Jenkins RL: Aggressive surgical resection for cholangiocarcinoma. Arch Surg 130: 270-276, 1995.

3 Roayaie S, Guarrera JV, Ye MQ, Thung SN, Emre S, Fishbein TM, Guy SR, Sheiner PA, Miller CM and Schwartz ME: Aggressive surgical treatment of intrahepatic cholangiocarcinoma: predictors of outcomes. J Am Coll Sug 187: 365-372, 1998.

4 Isaji S, Kawarada Y, Taoka H, Tabata M, Suzuki H and Yokoi $\mathrm{H}$ : Clinicopathological features and outcome of hepatic resection for intrahepatic cholangiocarcinoma in Japan. J Hepatobiliary Pancreat Surg 6: 108-116, 1999.

5 Nimura Y, Kamiya J, Kondo S, Nagino M, Uesaka K, Oda K, Sano T, Yamamoto H and Hayakawa N: Aggressive preoperative management and extended surgery for hilar cholangiocarcinoma: Nagoya experience. J Hepatobiliary Pancreat Surg 7: 155-162, 2000.

6 Miyazaki M, Ito H, Nakagawa K, Ambiru S, Shimizu H, Okaya $\mathrm{T}$, Shinmura $\mathrm{K}$ and Nakajima N: Parenchyma-preserving hepatectomy in the surgical treatment of hilar cholangiocarcinoma. J Am Coll Surg 189: 575-583, 1999.

7 Rea DJ, Munoz-Juarez M, Farnell MB, Donohue JH, Que FG, Crownhart B, Larson D and Nagorney DM: Major hepatic resection for hilar cholangiocarcinoma: analysis of 46 patients. Arch Surg 139: 514-525, 2004.

8 Hemming AW1, Reed AI, Fujita S, Foley DP and Howard RJ: Surgical management of hilar cholangiocarcinoma. Ann Surg 241: 693-702, 2005.

9 Chijiiwa $\mathrm{K}$ and Tanaka M: Carcinoma of the gallbladder: an appraisal of surgical resection. Surgery 115: 751-756, 1994. 
10 Sasaki R, Itabashi H, Fujita T, Takeda Y, Hoshikawa K, Takahashi M, Funato O, Nitta H, Kanno S and Saito K: Significance of extensive surgery including resection of the pancreas head for the treatment of gallbladder cancer - from the perspective of mode of lymph node involvement and surgical outcome. World J Surg 30: 36-42, 2006.

11 Yamaguchi R, Nagino M, Oda K, Kamiya J, Uesaka K and Nimura Y: Perineural invasion has a negative impact on survival of patients with gallbladder carcinoma. Br J Surg 89: 1130-1136, 2002.

12 Shimada M, Yamashita Y, Aishima S, Shirabe K, Takenaka K and Sugimachi K: Value of lymph node dissection during resection of intrahepatic cholangiocarcinoma. Br J Cancer 88: 1463-1466, 2001

13 Ohtsuka M, Ito H, Kimura F, Shimizu H, Togawa A, Yoshidome H, Shimamura F, Shimizu Y and Miyazaki M: Extended hepatic resection and outcomes in intrahepatic cholangiocarcinoma. J Hepatobiliary Pancreat Surg 10: 259-264, 2003

14 Uenishi T, Kubo S, Yamazaki O, Yamada T, Sasaki Y, Nagano $\mathrm{H}$ and Monden $\mathrm{M}$ : Indications for surgical treatment of intrahepatic cholangiocarcinoma with lymph node metastases. J Hepatobiliary Pancreat Surg 15: 417-422, 2008.

15 Nagino M, Ebata T, Yokoyama Y, Igami T, Sugawara G, Takahashi Y and Nimura Y: Evolution of surgical treatment for perihilar cholangiocarcinoma: a single-center 34-year review of 574 consecutive resections. Ann Surg 258: 129-140, 2013.

16 Morine Y, Shimada M, Utsunomiya T, Imura S, Ikemoto T, Mori H, Hanaoka J, Kanamoto M and Miyake H: Clinical impact of lymph node dissection in surgery for peripheral-type intrahepatic cholangiocarcinoma. Surg Today 42: 147-151, 2012.

17 Furuse J, Takada T, Miyazaki M, Miyakawa S, Tsukada K, Nagino M, Kondo S, Saito H, Tsuyuguchi T, Hirata K, Kimura F, Yoshitomi H, Nozawa S, Yoshida M, Wada K, Amano H and Miura F; Japanese Association of Biliary Surgery; Japanese Society of Hepato-Biliary-Pancreatic Surgery; Japan Society of Clinical Oncology: Guidelines for chemotherapy of biliary tract and ampullary carcinoma. J Hepatobiliary Pancreat Surg 15: 55$62,2008$.

18 Valle J, Wasan H, Palmer DH, Cunningham D, Anthoney A, Maraveyas A, Madhusudan S, Iveson T, Hughes S, Pereira SP, Roughton $\mathrm{M}$ and Bridgewater J; ABC-02 Trial Investigators: Cisplatin plus gemcitabine versus gemcitabine for biliary tract cancer. N Engl J Med 362: 1273-1281, 2010.

19 Sasaki T, Isayama H, Nakai Y, Ito Y, Kogure H, Togawa O, Toda N, Yasuda I, Hasebe O, Maetani I, Sasahira N, Hirano K, Tsujino $\mathrm{T}$, Tada $\mathrm{M}$ and Omata M: Multicenter, phase II study of gemcitabine and S-1 combination chemotherapy in patients with advanced biliary tract cancer. Cancer Chemother Pharmacol 65 : 1101-1107, 2010.

20 Kanai M, Yoshimura K, Tsumura T, Asada M, Suzuki C, Niimi M, Matsumoto S, Nishimura T, Nitta T, Yasuchika K, Taura K, Mori Y, Hamada A, Inoue N, Tada S, Yanagihara K, Yazumi S, Osaki Y, Chiba T, Ikai I, Fukushima M, Uemoto S and Hatano E: A multi-institution phase II study of gemcitabine/S-1 combination chemotherapy for patients with advanced biliary tract cancer. Cancer Chemother Pharmacol 67: 1429-1434, 2011.

21 Sasaki T, Isayama H, Nakai Y, Ito Y, Yasuda I, Toda N, Kogure H, Hanada K, Maguchi H, Sasahira N, Kamada H, Mukai T, Okabe Y, Hasebe O, Maetani I and Koike K: A randomized phase II study of gemcitabine and S-1 combination therapy versus gemcitabine monotherapy for advanced biliary tract cancer. Cancer Chemother Pharmacol 71: 973-979, 2013.

22 Takada T, Amano H, Yasuda H, Nimura Y, Matsushiro T, Kato $\mathrm{H}$, Nagakawa $\mathrm{T}$ and Nakayama T; Study Group of Surgical Adjuvant Therapy for Carcinomas of the Pancreas and Biliary Tract: Is postoperative adjuvant chemotherapy useful for gallbladder carcinoma? A phase III multicenter prospective randomized controlled trial in patients with resected pancreaticobiliary carcinoma. Cancer 95: 1685-1695, 2002.

23 Murakami Y, Uemura K, Sudo T, Hashimoto Y, Nakashima A, Sakabe R, Kobayashi H, Kondo N, Nakagawa N and Sueda T: Adjuvant chemotherapy with gemcitabine and S-1 after surgical resection for advanced biliary carcinoma: outcomes and prognostic factors. J Hepatobiliary Pancreat Sci 19: 306-313, 2012.

24 Murakami Y, Uemura K, Sudo T, Hayashidani Y, Hashimoto Y, Nakamura H, Nakashima A and Sueda T: Adjuvant gemcitabine plus S-1 chemotherapy improves survival after aggressive surgical resection for advanced biliary carcinoma. Ann Surg 250: 950-956, 2009.

25 Morine Y, Shimada M, Ikegami T, Imura S, Kanemura H, Arakawa Y, Hanaoka J, Kanamoto M and Nii A: Usefulness of gemcitabine combined with 5-fluorouracil and cisplatin (GFP) in patients for unresectable biliary carcinoma. Hepatogastroenterology 56: 307312, 2009.

26 Yamashita Y, Taketomi A, Itoh S, Harimoto N, Tsujita E, Sugimachi K, Gion $\mathrm{T}$ and Maehara Y: Phase II trial of gemcitabine combined with 5-fluorouracil and cisplatin (GFP) chemotherapy in patients with advanced biliary tree cancers. Jpn J Clin Oncol 40: 24-28, 2010.

27 Sobin LH, Gospodarowicz MK and Wittekind C (eds.): International Union Against Cancer (UICC): TNM Classification of Malignant Tumours. Seventh Edition. New York, NY: WileyLiss; 2009.

28 Jarnagin WR, Ruo L, Little SA, Klimstra D, D'Angelica M, DeMatteo RP, Wagman R, Blumgart LH and Fong Y: Patterns of initial disease recurrence after resection of gallbladder carcinoma and hilar cholangiocarcinoma: implications for adjuvant therapeutic strategies. Cancer 98: 1689-1700, 2003.

29 Hyder O, Hatzaras I, Sotiropoulos GC, Paul A, Alexandrescu S, Marques H, Pulitano C, Barroso E, Clary BM, Aldrighetti L, Ferrone CR, Zhu AX, Bauer TW, Walters DM, Groeschl R, Gamblin TC, Marsh JW, Nguyen KT, Turley R, Popescu I, Hubert C, Meyer S, Choti MA, Gigot JF, Mentha G, Pawlik TM: Recurrence after operative management of intrahepatic cholangiocarcinoma. Surgery 153: 811-818, 2013.

30 Jung SJ, Woo SM, Park HK, Lee WJ, Han MA, Han SS, Kim SH, Park SJ, Kim TH, Koh YH and Hong EK: Patterns of initial disease recurrence after resection of biliary tract cancer. Oncology 83: 83-90, 2012.

31 Ercolani G, Vetrone G, Grazi GL, Aramaki O, Cescon M, Ravaioli M, Serra C, Brandi G and Pinna AD: Intrahepatic cholangiocarcinoma: primary liver resection and aggressive multimodal treatment of recurrence significantly prolong survival. Ann Surg 252: 107-114, 2010.

32 Horgan AM, Amir E, Walter T and Knox JJ: Adjuvant therapy in the treatment of biliary tract cancer: a systematic review and meta-analysis. J Clin Oncol 30: 1934-1940, 2012.

33 Yamanaka K, Hatano E, Kanai M, Tanaka S, Yamamoto K, Narita M, Nagata H, Ishii T, Machimoto T, Taura K and Uemoto $\mathrm{S}$ : A single-center analysis of the survival benefits of adjuvant 
gemcitabine chemotherapy for biliary tract cancer. Int J Clin Oncol 19: 485-489, 2014.

34 Nakamura M, Nakashima H, Abe T, Ensako T, Yoshida K and Hino K: Gemcitabine-based adjuvant chemotherapy for patients with advanced gallbladder cancer. Anticancer Res 34: 31253129, 2014.

35 Cho M, Wang-Gillam A, Myerson R, Gao F, Strasberg S, Picus J, Sorscher S, Fournier C, Nagaraj G, Parikh P, Suresh R, Linehan D and Tan BR: A phase II study of adjuvant gemcitabine plus docetaxel followed by concurrent chemoradation in resected pancreaticobiliary carcinoma. HPB 17: 587-593, 2015.

36 Kainuma O, Miura F, Furukawa D, Yamamoto H, Cho A, Sano $\mathrm{K}$, Nakagohri $\mathrm{T}$ and Asano T: Feasibility and efficacy of gemcitabine plus cisplatin combination therapy after curative resection for biliary tract cancer. J Hepatobiliary Pancreat Sci 22: 789-794, 2015.

37 Park HJ, Kim K, Chie EK, Jang JY, Kim SW, Han SW, Oh DY, Im SA, Kim TY, Bang YJ and Ha SW: Chemoradiotherapy for extrahepatic bile duct cancer with gross residual disease after surgery. Anticancer Res 34: 6685-6690, 2014.

38 Nelson JW, Ghafoori AP, Willett CG, Tyler DS, Pappas TN, Clary BM, Hurwitz HI, Bendell JC, Morse MA, Clough RW and Czito BG: Concurrent chemoradiotherapy in resected extrahepatic cholangiocarcinoma. Int J Radiat Oncol Biol Phys 73: 148-153, 2009.

39 Kim TH, Han SS, Park SJ, Lee WJ, Woo SM, Moon SH, Yoo T, Kim SS, Kim SH, Hong EK, Kim DY and Park JW: Role of adjuvant chemoradiotherapy for resected extrahepatic biliary tract cancer. Int J Radiat Oncol Biol Phys 81: e853-859, 2011.

40 Hughes MA, Frassica DA, Yeo CJ, Riall TS, Lillemoe KD, Cameron JL, Donehower RC, Laheru DA, Hruban RH and Abrams RA: Adjuvant concurrent chemoradiation for adenocarcinoma of the distal common bile duct. Int J Radiat Oncol Biol Phys 68: 178-182, 2007.

41 Czito BG, Hurwitz HI, Clough RW, Tyler DS, Morse MA, Clary BM, Pappas TN, Fernando NH and Willett CG: Adjuvant external-beam radiotherapy with concurrent chemotherapy after resection of primary gallbladder carcinoma: a 23-year experience. Int J Radiat Oncol Biol Phys 62: 1030-1034, 2005.

42 Kresl JJ, Schild SE, Henning GT, Gunderson LL, Donohue J, Pitot H, Haddock MG and Nagorney D: Adjuvant external beam radiation therapy with concurrent chemotherapy in the management of gallbladder carcinoma. Int J Radiat Oncol Biol Phys 52: 167-175, 2002.

43 Glazer ES, Liu P, Abdalla EK, Vauthey JN and Curley SA: Neither neoadjuvant nor adjuvant therapy increases survival after biliary tract cancer resection with wide negative margins. J Gastrointest Surg 16: 1666-1671, 2012.
44 Wirasorn K, Ngamprasertchai T, Khuntikeo N, Pakkhem A, Ungarereevittaya $\mathrm{P}$, Chindaprasirt J and Sookprasert A: Adjuvant chemotherapy in resectable cholangiocarcinoma patients. J Gastroenterol Hepatol 28: 1885-1891, 2013.

45 Patel SH, Kooby DA, Staley CA 3rd, Sarmiento JM and Maithel SK: The prognostic importance of lymphovascular invasion in cholangiocarcinoma above the cystic duct: A new selection criterion for adjuvant therapy? HPB 13: 605-611, 2011.

46 Fisher SB, Patel SH, Kooby DA, Weber S, Bloomston M, Cho C, Hatzaras I, Schmidt C, Winslow E, Staley CA 3rd and Maithel SK: Lymphovascular and perineural invasion as selection criteria for adjuvant therapy in intrahepatic cholangiocarcinoma: a multiinstitution analysis. HPB 14: 514-522, 2012.

47 Kobayashi H, Murakami Y, Uemura K, Sudo T, Hashimoto Y, Kondo $\mathrm{N}$ and Sueda T: Human equilibrative nucleoside transporter 1 expression predicts survival of advanced cholangiocarcinoma patients treated with gemcitabine-based adjuvant chemotherapy after surgical resection. Ann Surg 256: 288-296, 2012.

48 Sasaki H, Murakami Y, Uemura K, Sudo T, Hashimoto Y, Kondo $\mathrm{N}$ and Sueda T: Concurrent analysis of human equilibrative nucleoside transporter 1 and ribonucleotide reductase subunit 1 expression increases predictive value for prognosis in cholangiocarcinoma patients treated with adjuvant gemcitabinebased chemotherapy. Br J Cancer 111: 1275-1284, 2014.

49 Peters GJ, Ruiz van Haperen VW, Bergman AM, Veerman G, Smitskamp-Wilms E, van Moorsel CJ, Kuiper CM and Braakhuis BJ: Preclinical combination therapy with gemcitabine and mechanisms of resistance. Semin Oncol 23(5 Suppl 10): 1624, 1996.

50 Reardon JT, Vaisman A, Chaney SG and Sancar A: Efficient nucleotide excision repair of cisplatin, oxaliplatin, and bis-acetoammine-dichloro-cyclohexylamine-platinum (IV) (JM216) platinum intrastrand DNA di-adducts. Cancer Res 59: 3968-3971, 1999.

51 Plunkett W, Huang P, Searcy CE and Gandhi V: Gemcitabine: preclinical pharmacology and mechanisms of action. Semin Oncol 23(5 Suppl 10): 3-15, 1996.

52 Schurz L, Schalhorn A and Wilmanns W: Synergic interaction of gemcitabine and 5-fluorouracil in colon cancer cells. Proc Am Soc Clin Oncol abstr 965, 1998.

53 Japanese Society of Biliary Surgery: General Rules for Surgical and Pathological Study on Cancer of the Biliary Tract, Fourth Edition. Tokyo: Kanehara; 1997. 